\title{
LA CONTINUIDAD DEL ESTADO NEOLIBERAL EN CHILE DURANTE LOS GOBIERNOS DEL PARTIDO SOCIALISTA
}

\author{
PABLO CARLOS ROJAS GÓMEZ ${ }^{{ }^{*}}$
}

\section{Resumen}

La presente investigación plantea la pregunta de por qué hay una adopción del neoliberalismo durante los gobiernos del Partido Socialista (PS). Para resolverla se parte de un enfoque de estudio del Estado como condensación de relaciones económicas y políticas.

La línea explicativa que se propone como respuesta al problema es que existieron dos ejes estructurales que impidieron al PS generar una nueva forma de Estado. Por un lado, se encuentra el eje económico que demuestra que el patrón exportador de producción especializada fue clave en la constitución de una burguesía subordinadamente asociada, como poder decisor en la vida de la sociedad chilena. Por otro lado se presenta el eje político: esa burguesía logró universalizar su proyecto y hegemonizarlo en un bloque de poder que perduró a pesar de la transición democrática.

Ambos ejes, el económico y el político han conformado estructuras poderosas del Estado chileno que el PS optó por administrar de manera flexible, sosteniendo las mismas alianzas del bloque de poder neoliberal.

\section{Palabras clave}

Neoliberalismo, partido socialista, estado, patrón de reproducción de capital, burguesía

\footnotetext{
$1 \quad{ }^{*}$ Licenciado en Ciencias Políticas y Administración Pública por la Universidad Nacional Autónoma de México, Maestro en Estudios Latinoamericanos por la UNAM. Dirección y contacto: Ciudad de México, México, pablocarlos.rojas@gmail.com
} 


\begin{abstract}
This research raises the question of why there is an adoption of neoliberalism during the Governments of the Socialist Party (PS). Solving it is part of an approach to study of the State as a condensation of economic and political relations. The explanatory line that is proposed as an answer to the problem is that there were two structural axes that made it impossible for the PS to generate a new form of State. On the one hand, is the economic hub which shows that the exporting pattern of specialized production was key in the Constitution of a conditionally associated bourgeoisie, as power decision-maker in the life of Chilean society. On the other hand presents the political axis: the bourgeoisie managed to universalize their project and hegemonizing in a block of power that lingered despite the democratic transition.
\end{abstract}

Both axes, the economic and the political have formed powerful structures of the Chilean State that the PS chose to manage in a flexible way, holding the same alliances of neoliberal power block.

\title{
Keywords
}

Neoliberalism, Socialist Party, State, pattern of reproduction of capital, bourgeoisie

\section{1.- Introducción}

No existe en América Latina parangón con el proceso de instauración del modelo neoliberal que se dio en Chile, pues, mientras que en otros países del continente dicho modelo fue asimilado en momentos de caídas de las dictaduras y transiciones democráticas, en Chile, el neoliberalismo se asignó bajo el cobijo proporcionado por la dictadura militar ${ }^{2}$. En un contexto de shock, represión y desarticulación de la oposición, se erigió la alianza entre el sector militar dirigido por Augusto Pinochet y el grupo de los Chicago Boys ${ }^{3}$, quienes sostuvieron como proyecto político-económico fundamental la doctrina neoliberal, a partir de la cual comenzaron un recetario con una serie de medidas como las siguientes: ${ }^{4}$ eliminación del control de

2 RUIZ, Carlos y BOCCARDO,Giorgio: Los chilenos bajo el neoliberalismo. Clases y conflicto social. El Desconcierto/ Nodo XXI, Santiago de Chile, 2015. p. 28.

3 HARVEY, David: Breve historia del neoliberalismo. Akal, Madrid, 2005.

4 GARRETÓN, Manuel Antonio: Neoliberalismo corregido, progresismo limitado. Los gobiernos de la Concertación en Chile, 1990-2010. CLACSO, Santiago, 2012. pp. 72-73. 
precios, liberalización de los flujos de capital internacional, liberación del mercado financiero, privatización de gran cantidad de empresas públicas, privatización de los sistemas de pensiones, salud y educación, eliminación del derecho a huelga y formación de sindicatos y gremios profesionales, cambio en las reformas tributarias para apoyar a los grandes consorcios empresariales trasnacionales

En ese sentido, el bloque de poder se conformó de la unión entre neoliberalismo y dictadura, una simbiosis entre lo militar y lo neoliberal' ${ }^{5}$. A partir de la centralización del poder y la fuerte represión, logró arrancarse de manera radical el patrón de reproducción de capital industrial, siendo sustituido por un patrón exportador de producción especializada y conllevando un barrido radical y profundo de las estructuras y actores consolidados durante el proceso nacional-popular, generando a su vez una reconfiguración clasista, con nuevas alianzas, nuevos actores y nuevas estructuras sociales ${ }^{6}$.

Bajo la primacía de la propiedad privada y un modelo de economía de libre mercado, se dio inicio al gran anhelo neoliberal que auguraba una supuesta disminución de la intervención del Estado en el mercado, pero que realmente implicó una profunda reestructuración social a partir de la dirección centralizada del Estado ${ }^{7}$. Fue desde la dirección política que se impuso una contrarrevolución capitalista que inició alterando además del patrón de reproducción del capital, el mapa del poder económico, impulsando el surgimiento de nuevos consorcios, empresas y conglomerados con niveles de acumulación y concentración de riqueza ${ }^{8}$ nunca antes vistos en la historia de Chile.

Esa acumulación desmedida fue ordenada y tutelada a partir de la dictadura, pues, gracias a la acción de Pinochet lograron colocarse en puestos clave de administración de empresas estatales a integrantes del grupo de los Chicago Boys, quienes a su vez lograron privatizarlas y transferirlas a manos de grupos económicos en alianza con capitales de la burguesía trasnacional. Esa transformación se dio de manera radical en todos los ámbitos de la vida pública, desde la prestación de servicios hasta las actividades productivas y comerciales primordiales para el país, desde el campo y las actividades agrícolas hasta los espacios de producción cultural y educativa.

5 MOULIAN, Tomás: Chile actual. Anatomía de un mito. LOM/Arcis, Santiago, 1997. p. 18. $6 \quad$ RUIZ y BOCCARDO, ob.cit., p. 10

7 BORÓN, Atilio: Estado, capitalismo y democracia. CLACSO, Buenos Aires, 2012.

8 FAZIO, Hugo: Los mecanismos fraudulentos de hacer fortuna. LOM, Santiago, 2016. 
La privatización fue un medio de transformación de la estructura económica social, política y cultural de Chile.

Más adelante, los funcionarios de la dictadura pasaron a administrar las empresas privatizadas impulsando la emergencia de una nueva burguesía con altísimos niveles de poder económico, que gracias a su capacidad de acumulación logró instaurarse como el actor fundamental de la vida nacional $^{9}$, consolidándose como el actor con mayor posibilidad de decisión e incidencia en todas las decisiones del rumbo social, es decir, con mayor capacidad de dirección social.

En paralelo con la gran contrarrevolución capitalista, aumentaron los niveles de desigualdad en un contexto de estado de shock y represión, frente a lo cual surgieron brotes de inconformidad que más tarde se canalizaron a través del plebiscito de 1988, en el que triunfó el "No" a la la dictadura.

Durante ese período se consolidó la formación de la Concertación de los Partidos por la Democracia, coalición que se dio a partir de la alianza entre la Democracia Cristiana (DC) y el Partido Socialista (PS). A esa coalición se sumarían más tarde partidos pequeños como el Partido Por la Democracia (PPD) y el Partido Radical Social Demócrata (PRSD).

Con una larga historia detrás, tanto la DC como el PS apostaron a ser oposición al régimen, pero sin conformar un nuevo proyecto político de largo aliento (Garretón 2012, 86), sin una propuesta de utopía u horizonte social, convirtiendo su alianza en un mero pacto pragmático persecutor de gobernabilidad.

Cuando el régimen civil-militar cesó, el gran reto para la sociedad chilena, y en especial para los gobiernos de la Concertación de Partidos por la Democracia, fue la superación de la herencia de la dictadura, sin embargo, lejos de ello, lo que se ha demostrado, es que el modelo neoliberal permaneció vigente ${ }^{10}$ a través de una transición pactada en los términos de la dictadura, los cuales sostenían las estructuras económicas y políticas fundamentales de esta. A raíz de eso se sucedieron 5 gobiernos de transición democrática:

1. 1990-1994 Presidencia de Patricio Aylwin (DC)

2. 1994-2000 Presidencia de Eduardo Frei Ruiz-Tagle (DC)

3. 2000-2006 Presidencia de Ricardo Lagos (PS) 
4. 2006-2010 Presidencia de Michelle Bachelet (PS)

5. 2014-2018 Reelección con intervalo ${ }^{11}$ de Michelle Bachelet (PS)

A pesar de lograr algunos triunfos en materia de derechos humanos y mejoría de programas sociales, los 5 gobiernos mantuvieron la continuidad el proyecto político-económico neoliberal de la dictadura, a partir de grandes pilares como la Constitución de 1980, el patrón de reproducción de capital, el rol subsidiario, restringido, represivo y focalizado del Estado y la hegemonía de la propiedad privada en no solo las relaciones de mercado, sino en todas las relaciones sociales y culturales del país ${ }^{12}$.

En ese sentido, los gobiernos posteriores a la dictadura fracasaron en términos de proporcionar un proyecto transformador que desterrara al proyecto social de la dictadura, pero sí consiguieron en cambio, generar un "neoliberalismo corregido" en consonancia con un "progresismo acotado"13. Eso quiere decir que se limitaron a la administración de las estructuras sociales heredadas por la dictadura y optaron por acomodarse a las nuevas formas de reproducción de la vida social.

Durante el período de los gobiernos de la Concertación, este orden se mantuvo perdurable, sin embargo, las movilizaciones de 2006 llegaron a poner en entredicho su estabilidad. Después de exigir carnet gratis, los estudiantes secundarios llegaron a cuestionar la Ley Orgánica Constitucional Para la Educación (LOCE), heredada de la dictadura, para no solo espetar el orden jurídico educativo, sino para reclamar que aquella promesa de ascenso social a través de la educación por lucro, no era más que una ilusión que fortalecía la competencia descarnada y sostenía un sistema educativo privado, privativo y exclusivo que no es más que un negocio de grandes conglomerados.

La revuelta de los pingüinos sacudió importantes sentidos comunes del relato de la Concertación y demostró que existía un gatopardismo que realmente protegía el orden socioeconómico de la dictadura, es decir, que había logrado adaptar al neoliberalismo bajo un discurso de supuesta preocupación social. Además, el movimiento logró superar su propio sector e integrar a otros estratos sociales que se manifestaron contra el lu-

11 La reelección de Michelle Bachelet se da después del gobierno del derechista Sebastián Piñera, quien gobernó entre 2010 y 2014.

12 RUIZ, Carlos: "Crisis política en Chile: neoliberalismo, cambios sociales y democracia”. En: Garretón, Manuel Antonio: La gran ruptura. Institucionalidad política y actores sociales en el Chile del siglo XXI. LOM, Santiago, 2016, pp. 83-108.

13 GARRETÓN, Neoliberalismo corregido, ob. cit. 
cro, contra la privatización de la educación y que iniciaron un proceso de reflexión sobre el imperio del mercado sobre lo social. En ese contexto, las aún más grandes movilizaciones estudiantiles de 2011, con la Confederación de Estudiantes de Chile (Confech) a la cabeza, fueron más lejos y proclamaron la necesidad de acabar con las lógicas del mercado, pero no solo eso, el 2011 consolidó la sacudida iniciada por el 2006, que demostró la expresión de un malestar social largamente acumulado y que ponía en duda ya no solo la autenticidad y voluntad de cambio de la Concertación, sino que representó un llamado a romper con la lógica neoliberal del Estado. Era la emergencia de un nuevo actor social, una nueva generación de jóvenes y también de movimientos sociales, hijos del neoliberalismo que los crió y los hizo crecer, pero que al mismo tiempo eran la expresión de las contradicciones de un proyecto político posterior a la dictadura pero sostenedor del mismo modelo económico.

Ese nuevo proceso de subversión frente al neoliberalismo continúa en marcha y redobla alientos con multitudinarias manifestaciones en contra del privado modelo de las Agencias de Fondos de Pensiones (AFP), en defensa del territorio y los recursos naturales, en contra de la centralización municipal y gubernamental, en contra de la terciarización y el outsourcing y finalmente también en contra de la corrupción de las instituciones, como lo demostraron los sorprendentes resultados tras las elecciones de 2017, en las que surgió un nuevo Frente Amplio, conformado de organizaciones estudiantiles nacionales como el Movimiento Autonomista, la Izquierda Autónoma, la Izquierda Libertaria, Revolución Democrática, la Unión Nacional Estudiantil, Poder, étc. Dicho frente logró colocar numerosos representantes suyos en espacios de representación como concejalías, diputaciones y una senaduría, además de haber alcanzado el $20 \%$ de la votación, apenas detrás del $23 \%$ del oficialista Alejandro Guillier, representante de la Nueva Mayoría.

En estas elecciones ganó nuevamente el derechista Sebastián Piñera, sin embargo, el Frente Amplio ha demostrado representar a un electorado que pugna por transformaciones profundas del modelo social, político y económico, y parece anunciar un posible período de disputa que aún se encuentra en entredicho.

Frente a estos hechos, el presente artículo intentará rebasar el carácter descriptivo del fenómeno de adaptación del neoliberalismo durante los gobiernos del Partido Socialista de Ricardo Lagos y Michelle Bachelet específicamente y buscará plantear una vertiente explicativa. Esto a través 
de un análisis de la conformación del bloque de poder hegemónico y las alianzas realizadas por parte del PS durante sus gobiernos, sin dejar de señalar que la acción del partido ha estado marcada por su propia conversión al centro político, por el vaciamiento de un horizonte histórico y por alianzas político-económicas con la burguesía neoliberal que han fungido como una concha de contención y renuncia al cambio. En suma, para explicar el fenómeno señalado, se partirá de un enfoque metodológico propio de un análisis relacional del Estado ${ }^{14}$, que piense a este más allá del conjunto de instituciones y aparatos de gobierno inmediatos y que más bien lo buscará estudiar como la condensación de relaciones de fuerza, de clase y de alianzas entre poder económico y poder político.

\section{2.- Cambios en la estructura socio-económica chilena y sustitución del patrón de reproducción industrial.}

La instauración de la dictadura y del modelo neoliberal significó un cambio radical en la estructura socioeconómica en Chile, generando un viraje abrupto en las formas y modos de reproducción económica nacional. Durante ese proceso, poco a poco se fue desmantelando la antigua estructura del patrón de reproducción de corte industrial para sustituirlo por un nuevo patrón exportador de producción especializa$\mathrm{da}^{15}$ que conformó una burguesía subordinadamente asociada con el capital trasnacional, lo cual quiere decir, que durante el período neoliberal de dictadura la estructura económica se modificó abandonando la postura que propugnaba por generar el desarrollo interno por la vía de la industrialización y la sustitución de importaciones y se optó por la apertura del mercado al capital trasnacional, orientando toda la estructura productiva del país hacia la exportación de materia prima, siempre en función de la demanda de las economías centrales. El legado de la dictadura fue la transformación radical de las relaciones de producción e intercambio económico y la modificación de la forma de reproducir el capital.

Además de lo anterior, lo importante a señalar aquí es que ese patrón exportador se mantuvo sin ningún cambio ni ruptura durante los gobier-

14 POULANTZAS, Nicos: Estado, poder y socialismo. Fondo de Cultura Económica, México, 1979 y JESSOP, Bob: "El Estado y el poder" En: Revista internacional de filosofia iberoamericana y teoría social, 2014, No. 19. pp. 19-35.

15 OSORIO, Jaime: Teoría marxista de la dependencia. Historia, fundamentos, debates y contribuciones. Itaca/UAM-X, México, 2016. 
nos de la transición democrática de la concertación, tal y como puede observarse en el siguiente cuadro.

Cuadro 1 Exportaciones de productos primarios 1988-2003

\begin{tabular}{|c|c|}
\hline Año & $\begin{array}{c}\text { Exportaciones de productos primarios } \\
\text { (Millones de USD) }\end{array}$ \\
\hline 1988 & 7.052 \\
\hline 1991 & 8.942 \\
\hline 1994 & 11.604 \\
\hline 1997 & 17.870 \\
\hline 2000 & 19.210 \\
\hline 2003 & 21,046 \\
\hline
\end{tabular}

Fuente: Elaboración propia a partir del documento "Economía chilena en cifras 1985-

2003"'/ Departamento de Estudios, Sociedad de Fomento Fabril (Sofofa)

Aunado a que las exportaciones se convirtieron en la actividad primordial de la vida económica chilena, estas giraron fundamentalmente en torno a mercancías de materia prima, es decir, la especialización se dio a partir de los requerimientos de los centros mundiales, centrándose en la producción extractivista, forestal y agropecuaria.

Cuadro 2 Especialización de la producción de exportaciones 1991-2003

\begin{tabular}{|c|c|c|c|c|}
\hline Año & $\begin{array}{c}\text { Exportación } \\
\text { de productos } \\
\text { de pescadería } \\
\text { (Millones de usd) }\end{array}$ & $\begin{array}{c}\text { Exportación de } \\
\text { vinos } \\
\text { (Millones de usd) }\end{array}$ & $\begin{array}{c}\text { Exportación de } \\
\text { celulosa } \\
\text { (Millones de usd) }\end{array}$ & $\begin{array}{c}\text { Exportación de } \\
\text { cobre } \\
* \text { (Miles de } \\
\text { toneladas } \\
\text { métricas) }\end{array}$ \\
\hline 1991 & 160 & 84 & 305 & 1.814 \\
\hline 1994 & 354 & 143 & 716 & 2.220 \\
\hline 1997 & 668 & 424 & 679 & 3.512 \\
\hline 2000 & 953 & 580 & 1.111 & 4.646 \\
\hline 2003 & 1.132 & 677 & 894 & 4.909 \\
\hline
\end{tabular}

Fuente: Elaboración a partir de datos de "Economía chilena en cifras 1985-2003"Departamento de Estudios, Sociedad de Fomento Fabril (Sofofa) 
Cabe mencionar que esas mismas actividades exportadoras de materia prima siguieron en constante crecimiento en los momentos más recientes de los gobiernos de la Concertación y particularmente durante el gobierno de la socialista Michelle Bachelet (Ver cuadro 3)

Cuadro 3 Exportaciones de materia prima 2013-2015 (Miles de millones de pesos chilenos)

\begin{tabular}{|c|c|c|c|c|}
\hline Año & $\begin{array}{c}\text { Exportación de } \\
\text { producción agrí- } \\
\text { cola-silvícola }\end{array}$ & $\begin{array}{c}\text { Exportación de } \\
\text { pescado }\end{array}$ & $\begin{array}{c}\text { Exportación de } \\
\text { celulosa }\end{array}$ & $\begin{array}{c}\text { Exportación de } \\
\text { cobre }\end{array}$ \\
\hline 2013 & 2,678 & 73 & 1,729 & 19,808 \\
\hline 2014 & 3,083 & 85 & 2,014 & 21,305 \\
\hline 2015 & 3,268 & 71 & 2,044 & 19,634 \\
\hline
\end{tabular}
Chile 2015",

Puede constatarse, entonces, que el patrón de reproducción, transformado durante dictadura, se mantuvo en constante auge durante los gobiernos de la Concertación, sin tener un cambio fundamental, ni siquiera durante los gobiernos del Partido Socialista. Ahora bien, si la llegada de la dictadura y del neoliberalismo a Chile implicó el barrido radical de un patrón de reproducción de capital y su sustitución por otro, ese escenario también conllevó el cambio en los actores sociales principales. A continuación procederemos a realizar el análisis correspondiente.

\section{3.- La constitución de la burguesía subordinadamente asociada.}

Una característica del neoliberalismo es que lejos de fomentar el libre mercado, lo que ha hecho es generar a partir de la intervención del Estado, una serie de modificaciones en los mapas de extrema riqueza ${ }^{16}$. De esa manera, lejos de permitir la libre competencia, en el caso chileno lo que realmente sucedió fue una concentración económica mayor, configurando poderosos monopolios en un contexto de instauración de un patrón de exportación de producción especializada y con ello el surgimiento de nuevos actores político-económicos en la escena nacional.

La dictadura significó una reconfiguración radical de la situación de la burguesía chilena, mientras la primera mitad del siglo XX representó la 
pugna por consolidar un orden económico que girara entorno a un proceso de industrialización, a partir del golpe de estado de 1973, se barrió con todo vestigio de la complicada burguesía industrial, instaurando un proceso de constitución de una nueva burguesía fruto del modelo neoliberal. Gracias al régimen autoritario que centralizaba el poder la dictadura se dedicó a impulsar una política paulatina pero acelerada de privatización (se estiman 30 privatizaciones de grandes empresas estatales en 15 años), que decantaría en una radical transformación del mapa de la extrema riqueza y más tarde conformó una nueva burguesía subordinadamente asociada, misma que proliferó gracias a fusiones e inversiones conjuntas con grandes sumas de inversión del capital extranjero trasnacional ${ }^{17}$.

Una de las características centrales de ese tipo de burguesía es que a pesar de llevarse a cabo asociaciones entre capitales chilenos y trasnacionales, siempre fueron los segundos los que primaron, pues el rol económico de las burguesías chilenas se restringió a dedicarse a las actividades agromineras $\mathrm{y}$ exportadoras ${ }^{18}$, es decir, a la producción de materia prima para satisfacer la demanda del mercado de las economías centrales, de ese modo, las asociaciones se llevaron a cabo con una burguesía trasnacional que imponía las reglas de intercambio comercial y el grado de especialización y una burguesía chilena subordinada que canalizaba la oportunidad de negocio para incrementar su poder adquisitivo y de acumulación al interior de Chile.

La asociación subordinada hacía primar a la burguesía trasnacional, pero fue funcional también para la burguesía chilena ya que le permitió entrar a nuevas esferas de acumulación y concentración de riqueza nunca antes vistas, lo que desde luego implicó un aumento en sus cuotas de poder político y en su capacidad de conducción de la sociedad.

Para el año de 1980, los empresarios exportadores representaban el $38,2 \%$ del total del empresariado agrícola, sin embargo para 2009, ya componían el 52,2\% del total, mientras que los empresarios no exportadores

17

Tales fueron los casos de las asociaciones entre la empresa Endesa España y la generadora chilena de energía eléctrica Enersis y la que tuvo lugar entre el Banco de Chile (grupo Luksic) y la red financiera estadunidense de Citibank, entre otros.

18 A diferencia de lo que podría pensarse, la contrarreforma agraria realizada por Pinochet, lejos de regresar el poder a la vieja oligarquía terrateniente chilena, realizó más bien una política de "modernización capitalista", generando una tecnologización de la industria agropecuaria, pero concentrando la producción en manos de nuevos empresarios provenientes del agronegocio trasnacional, lo que trajo consigo en ese rubro la acentuación del capitalismo agroexportador. RUIZ y BOCCARDO, ob. cit, p. 76. 
eran alcanzaban el $13,1 \%$ durante $2009^{19}$. Como puede observarse, la estructura de la burguesía agrícola fue modificándose, hasta conformarse como una clase dedicada a la comercialización exportadora de materia prima.

El rubro de la minería también fue explotado en mayor medida por la alianza entre la burguesía chilena y el capital extranjero, pues tan solo en 2012 la Inversión Extranjera Directa (IED) en minería representó el 49\% de todas las inversiones extranjeras, alcanzando un neto de USD $\$ 15.096$ millones $^{20}$.

A lo largo de 15 años (1975 - 1990) fueron privatizadas alrededor de 30 empresas pertenecientes a los rubros más importantes y estratégicos de la producción nacional. Entre estas podemos encontrar las siguientes: Empresa Nacional de Electricidad (Endesa) y filiales, Compañía de Acero del Pacífico (CAP), Industria Azucarera Nacional (Iansa), Línea Aérea Nacional (LAN Chile), Compañía de Teléfonos de Chile (CTC), Empresa Nacional de Telecomunicaciones (Entel).

Para el año de 2015, tan solo doce empresas concentraban el 50,2\% de toda la capitalización bursátil de Chile y de esas, solo tres sociedades empresariales concentraban el 25,8\%. Esas tres eran la italiana Enel (a través de sus alianzas con Enersis y Endesa), Falabella y $\operatorname{Copec}^{21}$. Lo anterior se apunta para demostrar que la oligopolización es una característica constante en el mapa de la extrema riqueza en Chile y que tiene como origen, la radical reconfiguración realizada por la dictadura. Fue a partir de ese momento que cambiaron las reglas del mercado y que mutaron los nichos empresariales, permitiendo fuertes niveles de concentración de excedente.

Para 2015, el mapa de los mayores patrimonios en términos brutos se conformaba de la siguiente manera:

Cuadro 4 Sociedades (empresas) con mayores patrimonios al 30 de septiembre de 2015

\begin{tabular}{|c|c|c|}
\hline Sociedad empresarial & $\begin{array}{c}\text { Patrimonio } \\
\text { (Millones de USD) }\end{array}$ & $\begin{array}{c}\text { Controlado por: } \\
\text { (Grupo controlador) }\end{array}$ \\
\hline Enersis & 11.616 & Enel (Italia) \\
\hline Minera Escondida & 11.505 & BHP Billiton (Inglaterra-Australia) \\
\hline Codelco & 11.426 & Estado chileno \\
\hline Antar Chile & 10.183 & Grupo Angelini \\
\hline Empresas Copec & 9.878 & Grupo Angelini \\
\hline
\end{tabular}

$19 \quad$ Íbid, p. 83 .

20 Íbid, p. 86.

21 FAZIO, ob. cit., p. 39. 


\begin{tabular}{|c|c|c|}
\hline Quiñenco & 8.662 & Grupo Luksic \\
\hline Empresas CMPC & 7.904 & Grupo Matte \\
\hline Forestal Arauco & 6.575 & Grupo Angelini \\
\hline Minera Valparaíso & 6.478 & Grupo Matte \\
\hline Falabella & 6.308 & Solari-Cúneo-Del Río \\
\hline Cencosud & 5.865 & Grupo Paulmann \\
\hline Endesa & 5.003 & Enel (Italia) \\
\hline Inversiones CMPC & 4.962 & Grupo Matte \\
\hline LQ Inversiones Financieras & 4.568 & Grupo Luksic-Citigroup (E.U.A.) \\
\hline Anglo American Sur & 4.482 & Anglo American (Inglaterra-Sudáfrica) \\
\hline Doña Inés de Collahuasi & 4.413 & Glencore (Suiza)- Anglo American \\
\hline Banco Santander de Chile & 3.840 & Banco Santander (España) \\
\hline Banco de Chile & 3.818 & Grupo Luksic-Citigroup (E.U.A.) \\
\hline
\end{tabular}

Como puede observarse, en este cuadro aparecen siete grandes grupos económicos de capital extranjero que se encuentran asociados con grupos económicos chilenos. En esa categoría están desde la empresa Enel, que es propietaria de otras empresas energéticas como Endesa (que anteriormente era dominada por capital español), Enersis y Chilectra' ${ }^{22}$; la alianza financiera entre el chileno Grupo Luksic y la estadunidense Citigroup; la alianza entre Empresas Copec del Grupo Angelini con la forestal estadunidense International Paper; la alianza entre Grupo Luksic y la cervecera Heineken a través de la empresa CCU; y hasta la alianza entre el Grupo Said y Coca-cola, de quien la primera se convirtió en empresa distribuidora en Chile a través de la empresa Embotelladora Andina ${ }^{23}$.

Por otro lado, como parte de los integrantes de la burguesía subordinadamente asociada, se pueden señalar tres grupos económicos que se encuentran de manera recurrente entre los conglomerados más poderosos del país: Grupo Angelini, Grupo Luksic, Grupo Matte. Los tres tienen como

22 José Yuraszeck adquirió la estatal Chilmetro, después de que esta fue privatizada, para después transformarla en Enersis. Esa empresa fue vendida a través de una gran estafa por parte de Yuraszeck hacia pequeños inversores, para pasar a ser posesión de Endesa España. Actualmente, tanto Enersis como Endesa se encuentran controladas por Enel, de capital italiano. Ver MÖNCKERBERG, Mónica: El saqueo de los grupos económicos al Estado chileno. Debolsillo, Santiago, 2015. 
común denominador su capacidad de supervivencia durante la transición, los tres sobrevivieron a las crisis económicas de la década de los ochenta, y también los tres se acoplaron a una mayor flexibilización respecto a su adherencia política una vez que arribaron los gobiernos de la Democracia Cristiana y del Partido Socialista, lo que les permitió sostener sus negocios, empresas y poderío económico, pero también influir en el panorama político y dar dirección al Estado chileno.

Actualmente, también estos grupos, junto con otros grandes conglomerados ingleses, australianos, canadienses, estadunidenses y sudafricanos, se encuentran entre los grandes exportadores de materia prima del país, especialmente la vinculada a la producción mineral y extractiva, como puede apreciarse en el siguiente cuadro.

Cuadro 5 Porcentaje de exportaciones según empresas y grupos económicos

\begin{tabular}{|c|c|c|}
\hline Empresa & $\begin{array}{l}\text { Porcentaje dentro del total } \\
\text { de exportaciones }\end{array}$ & $\begin{array}{l}\text { Grupo económico contro- } \\
\text { lador }\end{array}$ \\
\hline Codelco & $14,77 \%$ & Estado \\
\hline Minera Escondida & $8,76 \%$ & $\begin{array}{l}\text { BHP Billiton (Inglate- } \\
\text { rra-Australia) }\end{array}$ \\
\hline Anglo American Sur S.A. & $3,24 \%$ & \\
\hline Minera Los Pelambres & $3,20 \%$ & $\begin{array}{c}\text { Grupo Luksic (A través de } \\
\text { la sociedad Amsa) }\end{array}$ \\
\hline Metalúrgico Alto Norte S.A & $2,63 \%$ & Glencore (Suiza) \\
\hline $\begin{array}{l}\text { Minera Doña Inés de } \\
\text { Collahuasi }\end{array}$ & $2,51 \%$ & Anglo American y Glencore \\
\hline $\begin{array}{c}\text { Celulosa Arauco y Cons- } \\
\text { titución }\end{array}$ & $2,46 \%$ & Grupo Angelini \\
\hline Minera Centinela & $2,40 \%$ & Grupo Luksic \\
\hline Minera Spence S.A. & $1,75 \%$ & BHP Billiton \\
\hline CMPC Celulosa S.A. & $1,72 \%$ & Grupo Matte \\
\hline Minera Candelaria & $1,50 \%$ & Lundin Mining (Canadá) \\
\hline Minera El Abra & $1,35 \%$ & Freeport McMoRan (E.U.A.) \\
\hline Enami & $1,31 \%$ & Estado \\
\hline Minera del Pacífico & $1,15 \%$ & $\begin{array}{c}\text { CAP (Propiedad de Roberto } \\
\text { Andraca) }\end{array}$ \\
\hline Soquimich Salar S.A. & $0,94 \%$ & Julio Ponce de Lerou \\
\hline
\end{tabular}




\begin{tabular}{|c|c|c|}
\hline Anglo American Norte S.A. & $0,88 \%$ & $\begin{array}{c}\text { Audley Capital Advisors } \\
\text { (Inglaterra) }\end{array}$ \\
\hline Aserraderos Arauco S.A. & $0,84 \%$ & Grupo Angelini \\
\hline Fuente: Fazio, Hugo (2016). "Los mecanismos fraudulentos de hacer fortuna. Mapa de la \\
extrema riqueza 2015 ”, pp. $50-51$
\end{tabular}

Esto demuestra entonces, la conformación de una gran burguesía subordinadamente asociada con capitales extranjeros enfocada principalmente a la producción especializada de materia prima, misma que es exportada a los centros económicos mundiales, para abastecer su demanda de manera satisfactoria.

El rol histórico que jugó esa burguesía en la consolidación del proyecto neoliberal como proyecto social universalizado fue de gran calado, pues si bien se constituyó al alero de la dictadura siendo su principal beneficiada, tuvo la capacidad de hacer que el neoliberalismo perviviera a pesar de los cambios en la conducción política del Estado. La proyección histórica de clase de la burguesía subordinadamente asociada fue lo que permitió sostener el modelo a pesar del cambio de régimen político. Un ejemplo de lo expuesto fue el posicionamiento realizado durante los momentos de transición por parte de la Confederación de Producción y Comercio (CPC) dirigida en ese entonces por Manuel Feliú, en el que se aseguró que la victoria del "No" a la dictadura en el plebiscito de 1988 no era sinónimo a un rechazo al modelo económico por parte de la población, sino simplemente la necesidad de cambio político ${ }^{24}$.

Esa capacidad de conducción política por parte de la burguesía le permitió en los hechos, mantenerse como actor rector de las estructuras estatales, pues desde el primer momento los grupos económicos comenzaron a ser consultados de manera cotidiana y sistemática por los gobiernos concertacionistas en turno para poder aplicar políticas económicas, para definir el salario mínimo, para definir topes de impuestos ITASA, para activar el Tratado de Libre Comercio NAFTA. Todo eso lo hacían por medio de reuniones abiertas con la comisión de hacienda del parlamento y también con los ministros, con recepciones en la moneda y participaciones activas de representantes del gobierno en foros de empresarios y a través de la prensa. En ese sentido, "se ha exagerado la supuesta capacidad de adaptación del gran empresariado, en el marco de un escenario político que les fue favorable para mantener tanto su protagonismo político como importancia eco-

24 ÁLVAREZ VALLEJOS, Rolando: Gremios empresariales, politica y neoliberalismo. Los casos de Chile y Perú (1986-2010). LOM, Santiago, 2015. p. 52. 
nómica. Por el contrario, la adaptación fue más bien del sistema político, que debió acostumbrarse a que el gran empresariado impusiera su propia agenda político/económica" 25 .

\section{4.- El viraje ideológico del Partido Socialista y sus alianzas con la burguesía chilena.}

El viraje ideológico del PS al interior de la Concertación representó un giro de $180^{\circ}$, convirtiéndose en un engrane clave para la pervivencia del neoliberalismo con una cara social y programas focalizados para sectores pobres, al tiempo en que renunciaba a la política transformadora llamando a "enmendar el modelo de desarrollo"26.

La mutación del PS inició desde los tiempos de la persecución y del exilio, llegando a asimilar tesis de negación de la propuesta revolucionaria, optando por una vía de distribución del ingreso (no de la riqueza) y también divorciándose abruptamente de la política de los movimientos y organizaciones sociales. Durante sus años de gobierno la institucionalidad neoliberal no fue trastocada, y al contrario, los nichos del bloque de poder neoliberal se mantuvieron a través de pactos y alianzas con la burguesía subordinadamente asociada. Entre las explicaciones que han hipotetizado al respecto diferentes autores, se ha sugerido que los gobiernos de la concertación asumieron el chantaje de la posibilidad de un retorno del autoritarismo, por lo cual, según esta idea, sería necesario apostar siempre al "centro" político y al sostenimiento del orden heredado por la dictadura ${ }^{27}$, en ese sentido el PS ha preferido situarse en una posición de supuesta neutralidad estatal, apostando por administrar y conducir el régimen dominado por el proyecto universalizado de la burguesía chilena.

El partido, ha aceptado sin discusión la lógica del mercado, comprando la argumentación conservadora de que el Estado representa necesariamente "estatismo" y "autoritarismo" y el mercado la libertad y la democracia ${ }^{28}$, lo cual quiere decir que el Partido Socialista ha abrigado conceptualizaciones

\footnotetext{
$25 \quad$ Íbid, p. 74

26 VALENZUELA, Esteban: La conversión de los socialistas chilenos. Esquema de transformación político-cultural de una élite desde la revolución al orden. El Desconcierto, Santiago, 2014. p. 86.

27 HUNEEUS, Carlos: La democracia semisoberana: Chile después de Pinochet. Taurus, Santiago de Chile, 2014.

28 VALENZUELA, ob. cit.
} 
clave de las propuestas ideológicas del neoliberalismo, configurando con ello una adherencia a sus sentidos comunes ${ }^{29}$.

El actuar de la Concertación en general, pero específicamente el del Partido Socialista ha sido clave en la legitimación del modelo, anulando todo tipo de oposición extrainstitucional y eliminando también un potencial polo transformador al interior del mapa político durante el período de la transición democrática. Dicho de otro modo, el proyecto de socialismo del PS se difuminó pasando por la renuncia a un proyecto transformador del orden social y mutando hacia un proyecto capitalista de adopción del neoliberalismo con componentes de beneficio social. Se pasó del proyecto socialista al proyecto social-neoliberal.

A pesar de las esperanzas vertidas en la transición, esta resultó ser un acuerdo entre élites organizadas que soterró la participación social bajo la decisión cupular acotada, configurando un pacto a espaldas de la socie$\mathrm{dad}^{30}$, pero no solo eso, lejos de empujar una reestructuración del bloque de poder, la salida pactada fue una mera sustitución del grupo gobernante, que se paró sobre la institucionalidad heredada sin un cambio de fondo en la alianza dominante.

La transición fue entonces un cambio de gobierno, pero con la continuidad del mismo bloque de poder, que se caracterizó por el afianzamiento del principal actor de la dictadura como dirigente y actor hegemónico: la burguesía subordinadamente asociada, hija de la dictadura. Beneficiaria de la acción estatal neoliberal, monopólica, aliada del capital extranjero que era recibido con los brazos abiertos, demostró ser la clase dirigente de un Estado neoliberal que representó sus intereses sin contrapesos, tapujos ni mediaciones generales. El Estado chileno se consolidó como el representante crudo de la burguesía chilena, en demérito, desde luego, de la participación social y esas fueron las ataduras estructurales que impidieron al PS generar una transformación de fondo en el Estado, optando por administrar de manera más flexible y con un tinte social el Estado neoliberal.

Durante el primer gobierno del PS de Ricardo Lagos la posición de los empresarios hacia este y hacia su ministro de hacienda Nicolás Eyzaguirre era rotundamente positiva, a tal grado que se pasó del "tenemos un presidente de lujo, absolutamente de lujo" de Andrónico Luksic al "Mis empresarios aman a Lagos" de Hernán Somverville ${ }^{31}$, y cómo no iba a ser

$29 \quad$ MOULIAN, ob. cit.

30 RUIZ, ob. cit., p. 68.

31 ÁLVAREZ, ob. cit. 
así si el mismo presidente había aceptado ser el administrador de un orden plenamente neoliberal bajo la batuta de la burguesía chilena, tal y como lo demuestra la relación de su gobierno con los empresarios a partir de la intervención de dirigentes de la Sociedad de Fomento Fabril (Sofofa) y de la Confederación de la Producción y del Comercio (CPC) la "Agenda Pro Crecimiento" del año 2002 y los encuentros entre el presidente y la burguesía como la entrevista que se suscitó en el Centro de Estudios Políticos (CEP) con el grupo Matte, grupo Angelini, grupo Luksic, Lamarca, Copec y Quiñenco asumiendo una relación de negociación/subordinación entre la burguesía y el Estado.

Esa política de alianzas no se modificó durante los gobiernos de Michelle Bachelet, quien incluso recibió el apoyo de la CPC durante las manifestaciones estudiantiles de 2006, dando lugar a un momento en el que de hecho se llegaron a plantear mayores exenciones tributarias a los empresarios

A continuación se presenta un recuento de cómo puede observarse la alianza entre el Gran Empresariado chileno y los gobiernos "socialistas":

Tabla 1 Ministros del PS en alianza con grupos económicos

\begin{tabular}{|c|c|c|c|c|c|}
\hline Gobierno & Ministro vinculado & $\begin{array}{c}\text { Grupo } \\
\text { Económico }\end{array}$ & Empresas & Cargo Ejercido & Partido \\
\hline M. Bachelet & Nicolás Eyzaguirre & Luksic & Canal 13 & $\begin{array}{c}\text { Ministro de Educación (2014- } \\
\text { 2015). Ministro secretario } \\
\text { general de la presidencia (2015) }\end{array}$ & PPD \\
\hline M. Bachelet & Alberto Arenas & Luksic & Canal 13 & $\begin{array}{c}\text { Director de Presupuestos (2006- } \\
\text { 2010). Ministro de Hacienda } \\
\text { (2014-2016) }\end{array}$ & PS \\
\hline M. Bachelet & $\begin{array}{c}\text { Máximo Pacheco } \\
\text { Matte }\end{array}$ & $\begin{array}{c}\text { Angelini/ } \\
\text { Luksic }\end{array}$ & $\begin{array}{c}\text { Provida, } \\
\text { Lucchetii, } \\
\text { Falabella y } \\
\text { Banco de Chile }\end{array}$ & $\begin{array}{c}\text { Ministro de Energía (2014-2016) } \\
\text { PS }\end{array}$ & PSile, \\
\hline M. Bachelet & Aurora Williams & Luksic & $\begin{array}{c}\text { Aguas de } \\
\text { Antofagasta }\end{array}$ & Ministra de Minería (Desde & 2014) \\
\hline M. Bachelet & Vivianne Blanlot & $\begin{array}{c}\text { Luksic/ } \\
\text { Matte }\end{array}$ & $\begin{array}{c}\text { Antofagasta } \\
\text { PLC/Colbún }\end{array}$ & Ministra de defensa (2006-2007) & PPD \\
\hline M. Bachelet & René Cortázar & Luksic & Canal 13 & $\begin{array}{c}\text { Ministro de Transportes (2007- } \\
\text { 2010) }\end{array}$ & PDC \\
\hline
\end{tabular}




\begin{tabular}{|c|c|c|c|c|c|}
\hline M. Bachelet & Gustavo Arriagada & Saieh & Corpbanca & $\begin{array}{l}\text { Superintendente de Bancos } \\
\text { e Instituciones Financieras } \\
\quad(2006-2010)\end{array}$ & Indep \\
\hline M. Bachelet & Alejandro Ferreiro & Saieh & Corpvida & $\begin{array}{l}\text { Ministro de Economía (2006- } \\
\text { 2008) }\end{array}$ & PDC \\
\hline R. Lagos & Nicolás Eyzaguirre & Luksic & Canal 13 & $\begin{array}{l}\text { Ministro de Hacienda (2000- } \\
\text { 2006) }\end{array}$ & PPD \\
\hline R. Lagos & $\begin{array}{l}\text { Jaime } \\
\text { Estévez }\end{array}$ & Luksic & Banco de Chile & $\begin{array}{c}\text { Ministro de Obras } \\
\text { Públicas (2005-2006). } \\
\text { Ministro de Transportes y } \\
\text { Telecomunicaciones(2005-2006) }\end{array}$ & PS/PPD \\
\hline R. Lagos & $\begin{array}{c}\text { José } \\
\text { de Gregorio }\end{array}$ & Luksic & $\begin{array}{c}\text { Cía } \\
\text { Sudamericana } \\
\text { de Transportes }\end{array}$ & $\begin{array}{l}\text { Ministro de Economía (2000- } \\
\text { 2001)Ministro de Minería (2000- } \\
\text { 2001) Ministro presidente de la } \\
\text { Comisión Nacional de Energía } \\
\text { (2000-2001) }\end{array}$ & PDC \\
\hline R. Lagos & Alejandro Ferreiro & Saieg & Corpvida & $\begin{array}{c}\text { Superintendente de } \\
\text { Electricidad y Combustibles } \\
\text { (2000). Superintendente de } \\
\text { Administradoras de Fondos } \\
\text { de Pensiones (2000-2003). } \\
\text { Superintendente de Valores y } \\
\text { Seguros (2003-2006). }\end{array}$ & PDC \\
\hline
\end{tabular}

Fuente: Elaboración a partir de Matamala, D. (2015) Poderoso caballero. El peso del dinero en la política chilena. Santiago de Chile: UDP

Como puede observarse, el socio mayoritario de los gobiernos del PS fue el Grupo Luksic, quien mantuvo tres ministros durante el gobierno de Ricardo Lagos y seis durante los gobiernos de Michelle Bachelet en carteras fundamentales como las de Hacienda, Economía, Minería, Transportes, AFPs, étc.

De entre los ministros que manejaban vínculos más preponderantes resalta la presencia de Nicolás Eyzaguirre, ministro de Hacienda entre 2000 y 2006, pieza fundamental en los cabildeos entre Ricardo Lagos y los empresarios, quien además tuvo continuidad con Bachelet, como ministro de Educación.

Otros personajes importantes a señalar son Máximo Pacheco, quien ejerció en numerosos directorios de consorcios (Banco de Chile, AFP Provida, Lucchetii, Falabella y Banco de Chile) incluso con distintos grupos económicos, (Angelini y Luksic); Aurora Williams, quien fuera activista directa desde su posición en el gobierno en pro de Grupo Luksic en el caso de la reserva Los Pelambres, que sostenía un fuerte conflicto por delimitación de 
territorios y límites con Argentina ${ }^{32}$; y Alejandro Ferreiro, quien fungiera como Superintendente de Administradoras de Fondos de Pensiones entre 2000 y 2003, a pesar de pertenecer directamente a la empresa Corpvida, aseguradora y clara interesada en asuntos de pensiones y seguros de vida.

Durante el gobierno de Ricardo Lagos se aprobó una Ley durante el año de 2003 que buscaba cambiar las lógicas de financiamiento de las campañas electorales, para regular de mejor manera el dinero privado destinado a política. Sin embargo, después de un importante cabildeo con la derecha, la Concertación aceptó autorizar donaciones de empresas, con mínimas medidas regulatorias ${ }^{33}$. Ya para 2013, el Servicio Electoral de Chile (Servel) calculaba que los aportes privados a campañas eran de 76,8 millones de dólares, sin embargo, existen confesiones como la del ex alcalde de Santiago Jaime Ravinet que aseguró que a pesar de que no se podían exceder los 80 millones de pesos chilenos, llegó a recibir 400 millones.

Las campañas electorales se han convertido en el mayor espacio de disputa por parte de los grupos económicos de la burguesía y aunque se ha intentado regular dicha actividad, lo cierto es que se mantienen abiertos candados importantes, que permiten a un mismo grupo económico financiar a diversos candidatos o partidos a través de distintas empresas, pues aunque se fije un tope máximo de aportaciones, evaden este problema utilizando a sus diferentes empresas, sin rebasar el tope.

Como puede verse en el siguiente cuadro el Grupo Luksic ha podido realizar 47 aportes a través de 20 empresas de su conglomerado. El Grupo Matte ha hecho 75 aportes a través de 36 empresas y el Grupo Angelini ha realizado 60 aportes a partir de 20 empresas.

Cuadro 6 Aportaciones de Grupos Económicos a campañas políticas ${ }^{34}$

\begin{tabular}{|c|c|c|c|}
\hline Grupo Económico & $\begin{array}{c}\text { Activos (Millones } \\
\text { de dólares) }\end{array}$ & $\begin{array}{c}\text { Número de Empre- } \\
\text { sas aportantes }\end{array}$ & Total de aportes \\
\hline Luksic & 63,029 & 20 & 47 \\
\hline Matte & 38,248 & 36 & 75 \\
\hline Yarur & 37,102 & 8 & 24 \\
\hline Angelini & 31,054 & 20 & 60 \\
\hline
\end{tabular}

32 MATAMALA, Daniel: Poderoso caballero. El peso del dinero en la politica chilena. Catalonia/Periodismo-UDP, Santiago, 2015, p. 147.

33 Íbid, p. 101.

34 Datos actualizados en dólares. Íbid, p. 116 
Desde inicios del año 2015 la corrupción política se convirtió en un tema recurrente en Chile, puesto que estallaron distintos casos de intercambios de favores de actores políticos hacia grandes empresas a cambio de dinero justificado con boletas o recibos de cobro falsas. No hubo un solo partido político que no se viera alcanzado por eso, sin embargo, resaltan de entre los casos las triangulaciones articuladas por Rodrigo Peñailillo y Giorgio Martelli para recaudar fondos para la campaña de Bachelet, llegando a recibir dinero de Julio Ponce Lerou, ex yerno de Augusto Pinochet y dueño de la empresa Soquimich (SQM) y de José Tomás Guzmán, representante de los Angelini ${ }^{35}$.

¿Por qué es importante señalar lo anterior? Porque ahí se evidenció de otra manera una profunda alianza entre el gobierno del Partido Socialista y el poder económico dominante de la burguesía y la capacidad de esta última para dominar completamente el terreno de la política en Chile.

\section{5.- Discusión y conclusiones}

Como se expuso anteriormente, al alero de la dictadura de Augusto Pinochet, se impuso el surgimiento de un nuevo patrón de reproducción de capital, pero también la hegemonía incuestionable de una burguesía subordinadamente asociada con una burguesía trasnacional, que permitió generar un cuadro de privatizaciones de los servicios y empresas público-estatales y la consolidación de la primacía del patrón de extracción y exportación de cobre, pescadería, vinos, celulosa y papel. Esa burguesía, beneficiada por la contrarrevolución capitalista de la dictadura e hija del nuevo patrón exportador de producción especializada, se conformó como el actor social más preponderante en el mapa político de Chile, lo que le permitió establecerse en una posición privilegiada al interior de un nuevo bloque de poder en alianza con el gobierno militar de Pinochet y el grupo de tecnócratas de los Chicago Boys.

Las relaciones de poder en las que primó la burguesía de manera abierta y desnuda, devinieron reglas y esas reglas eran ya instituciones que durante la transición democrática permitieron sostener un mismo orden social con un nuevo consenso pactado desde arriba, sin la sociedad, pero que dotaba al bloque de poder de una nueva legitimidad pues la Concertación se caracterizó por apropiarse de la democracia como bandera, a pesar de que esa democracia fuera restringida y restrictiva de la participación social.

$35 \quad$ Íbid, p. 43. 
La experiencia de los gobiernos del PS fue la confirmación de que la burguesía lejos de ceñirse al poder político, realmente había desarrollado una novedosa capacidad de articular de manera transparente el poder económico y el poder político e imponer desde el primero la dirección al segundo. El PS en ese sentido renunció a la transformación del Estado neoliberal y optó por reproducir las alianzas y estructuras sociales que le daban sustento, dejando en claro que no importa en gran medida el color del partido gobernante, mientras se someta a las lógicas de la burguesía, reproduzca el patrón exportador de producción especializada y aceite de manera adecuada la hegemonía neoliberal.

Las estructuras del Estado neoliberal y la constitución de un patrón exportador de producción especializada sí conformaron entonces las ataduras fundamentales que permiten seguir hablando de un Estado neoliberal a pesar de haber gobernado partidos con orientación social y discurso progresista como sucedió con el caso del Partido Socialista. He ahí la explicación del por qué no hubo cambio del Estado neoliberal a pesar de haber gobernado el Partido Socialista, con una fuerte tradición de lucha popular de izquierda.

En resumen, lo que se plantea en este artículo es que la burguesía subordinadamente asociada se conformó durante la dictadura como el actor rector de la sociedad chilena en su conjunto, consiguiendo establecer un poderío económico de tal manera que este se tradujo en una gran fuerza política, capaz de hacer que por más que hubiera cambio de los partidos gobernantes o incluso una transición democrática que sacara a la dictadura, el poder político se ciñera a las reglas establecidas por la burguesía, es decir, los grupos políticos tenían que ceñirse a continuar con la reproducción del modelo neoliberal y el bloque de poder emanado de este. Por ello, el vaciamiento ideológico de izquierda que vivió el Partido Socialista y su giro hacia el centro, fue acompañado de una aceptación tácita de la institucionalidad neoliberal y sus estructuras, excluyendo al grueso de la sociedad de la toma de decisiones. La sociedad en ese sentido no fue vista como un actor clave de transformación con el cual era importante aliarse para transformar el modelo. El PS a la larga apostó por la administración con tintes sociales del modelo neoliberal debido a la capacidad de poder de la burguesía y de su posibilidad de conducir y dirigir el destino de la sociedad chilena toda.

Siguiendo ese marco explicativo, aunque Michelle Bachelet haya ganado las elecciones de 2014 con un discurso en pro de los movimientos sociales y retomando sus principales demandas, -como lo fue su propuesta 
de cambio de constitución o lograr educación gratuita-, tuvo que ceñirse a las reglas del juego, demostrando que tomó esas demandas solo como meras banderas vacías, sin respaldarlas de un proyecto transformador, por tanto, el PS se mantuvo subordinado a su propia posición neoliberal y de alianza de representación con la burguesía chilena, habiendo renunciado en paralelo a la disputa de la dirección del Estado, dejando ese rol en manos de la burguesía subordinadamente asociada.

En marzo de 2015, algunas encuestas dieron a conocer la más baja aprobación del gobierno de la presidenta Michelle Bachelet ${ }^{36}$ lo que provocó una lluvia de explicaciones que señalaron al fenómeno como una crisis de confianza en la institucionalidad ${ }^{37}$.

Pero cuando se habla de que hay una crisis de falta de confianza en las instituciones, suele pensarse como un elemento meramente institucional o meramente gubernamental, que en ese sentido, podría solucionarse a partir de echar a andar políticas públicas, reformas y acciones del gobierno para recuperar la confianza de la ciudadanía. En ese sentido bastaría con un cambio de partido y de dirección del gobierno, que permitiesen la aplicación de medidas para mejorar la gobernanza y la gobernabilidad. Varios autores de inmediato realizaron balances, elogios y críticas que se restringían a proporcionar recomendaciones y perspectivas de cómo evitar la colusión entre poder político y poder económico, reduciendo el problema a un problema de partidos ${ }^{38} \mathrm{o}$ a un problema que incitaba a buscar formas de separación entre política y economía ${ }^{39}$.

Dando continuidad a los problemas metodológicos de raíz que sostiene hoy día la ciencia política, los análisis actuales olvidan u obvian que el problema atiende a cuestiones estructurales y concernientes a las relaciones sociales y al mapa de correlación de fuerzas entre los distintos actores de la vida pública y no meramente de la esfera legal e institucional reconocida.

36 Encuesta de Evaluación de Gestión de Gobierno, 2015 [http://www.adimark.cl/es/ estudios/documentos/13_eval\%20gobierno\%20mar_2015.pdf]

37 BAROZET, Emmanuelle. "Entre la urna, las redes sociales y la calle: las relaciones entre movimientos sociales y partidos políticos en el Chile democrático". En: Garretón, Manuel Antonio: La gran ruptura. Institucionalidad politica y actores sociales en el Chile del siglo XXI. LOM, Santiago, 2016. DE LA MAZA, Gonzalo. "Sociedad civil, ciudadanía, movimiento social en el Chile de hoy. En: Garretón, Manuel Antonio: La gran ruptura. Institucionalidad politica y actores sociales en el Chile del siglo XXI. LOM, Santiago, 2016

38 FUENTES, Claudio. "La reforma a los partidos políticos. Modelos en pugna". En: Garretón, Manuel Antonio: La gran ruptura. Institucionalidad política y actores sociales en el Chile del siglo XXI. LOM, Santiago, 2016

39

BAROZET, ob. cit. y DE LA MAZA, ob. cit. 
La explicación de la desconfianza en las instituciones que según los autores citados puede combatirse a partir del acotamiento del poder económico desde la institucionalidad política, tiene como limitante principal que se analiza desde una posición metodológica que piensa que existe realmente una separación entre la esfera de lo económico y la de lo político, cuando la unidad de ambas constituye en sus raíces al Estado neoliberal chileno de hoy en día, pero que sobretodo, esa unidad es la que permite sostener la alianza dominante del bloque de poder en el que prima el empresariado. Es importante cambiar de enfoque teórico-metodológico y optar por estudiar al Estado más bien como un mapa de correlación de fuerzas de actores económicos y políticos intrínsecamente interrelacionados.

Lo que desnudan los índices de aprobación en conjunto con las nuevas protestas sociales tiene que ver más bien con que Chile asiste a un proceso de desgaste de la alianza entre los gobiernos de la concertación y las clases económicas dominantes. La falta de credibilidad sí representa un peligro, pero para la institucionalidad nacida de un régimen ilegítimo que se instauró por la fuerza y perduró a través de alianzas que no fueron sometidas a consulta, por ello, es importante decir que la hegemonía impuesta es una hegemonía nacida de la corrupción de la institucionalidad. La alianza dominante se encuentra fuertemente cuestionada y difícilmente se restablecerá por vías institucionales (que se sustentan en una institucionalidad cuestionada y corrompida) y ahora se abre la posibilidad de observar qué papel jugará la sociedad en la propuesta de una nueva política.

Como consecuencia, hoy día comienzan a emerger nuevos actores colectivos desde la sociedad que buscan hacerse valer como protagonistas de la política nacional. Ese nuevo ciclo empezó a gestarse desde la revuelta de los estudiantes secundarios en 2006 y los universitarios de 2011. Desde entonces, ha surgido un abanico amplio de protestas en contra de la centralización territorial que excluye a las regiones, a partir de movimientos en defensa del agua, movimientos feministas masivos, protestas de pesqueros, y lo más reciente y sorprendente ha sido la protesta contra el esquema de privatización de las Agencias de los Fondos de Pensiones (AFPs) trastocando la columna vertebral del modelo, pues han sido las AFPs el instrumento por medio del cual los grupos económicos han logrado capitalizarse y expandirse al mercado regional latinoamericano ${ }^{40}$. 
La legitimidad del orden social neoliberal cada vez se encuentra más cuestionada por los movimientos sociales y eso ha demostrado que aquella no puede retejerse desde la misma institucionalidad, no desde ahí. Por eso no es extraño la incomprensión de los grupos gobernantes frente a fenómenos como el surgimiento de un nuevo Frente Amplio que agrupa organizaciones sociales que no provienen de los partidos políticos tradicionales, sino de nuevas fuerzas sociales que demandan construir una nueva relación Estado-Sociedad, colocando figuras novedosas en candidaturas a espacios de representación política, como fue el caso de la periodista Beatriz Sánchez, candidata externa al sistema de partidos, quien quedó a solo 3 puntos de Alejandro Guillier, candidato de la Nueva Mayoría. La incapacidad de Guillier para entender cuáles son las nuevas demandas de la sociedad, que sí logró canalizar el Frente Amplio, le generó la imposibilidad de atraer esos votos en la segunda vuelta frente al ultraderechista Sebastián Piñera.

Aún queda pendiente ver si las fuerzas sociales son capaces de construir una nueva alianza lo suficientemente fuerte como para reconfigurar el bloque de poder dominante y revertir la subordinación del poder político bajo el poder económico de la burguesía. Ante la renuncia de los partidos y del gobierno de la posibilidad de acotar el poder económico, la sociedad excluida durante años surge como un nuevo actor que sería el único capaz de cumplir la tarea de limitar la fuerza económica de la burguesía y de su hegemonización rotunda que domina cada una de las capilaridades de la vida social chilena.

\section{Bibliografía}

ÁlVAREZ VALLEJOS, Rolando: Gremios empresariales, política y neoliberalismo. Los casos de Chile y Perú (1986-2010). LOM, Santiago, 2015.

BAROZET, Emmanuelle: "Entre la urna, las redes sociales y la calle: las relaciones entre movimientos sociales y partidos políticos en el Chile democrático". En: Garretón, Manuel Antonio: La gran ruptura. Institucionalidad política y actores sociales en el Chile del siglo XXI. LOM, Santiago, 2016.

BORÓN, Atilio: Estado, capitalismo y democracia. Clacso, Buenos Aires, 2012. 
CAVIEDES, Sebastián: "Cuando un crédito por $\$ 6.500$ millones poco importa. La verdadera influencia empresarial de grupo Luksic". En: Cuadernos de coyuntura (Nodo XXI), $\mathrm{n}^{\circ} 7$ (abril 2015). pp. 37-50.

CAVIEDES, Sebastián y BUSTAMANTE, Andrés: "El papel de la tradición: la influencia empresarial del grupo Matte". En: Cuadernos de coyuntura (Nodo XXI), no 8 (junio 2015). pp. 40-55.

CAVIEDES, Sebastián y BUSTAMANTE, Andrés: "La red de arrastre estatal: la influencia empresarial del grupo Angelini”. En: Cuadernos de coyuntura, $\mathrm{n}^{\circ} 9$ (agosto 2015), pp. 1-13.

DE LA MAZA, Gonzalo: "Sociedad civil, ciudadanía, movimiento social en el Chile de hoy. En: Garretón, Manuel Antonio: La gran ruptura. Institucionalidad política y actores sociales en el Chile del siglo XXI. LOM, Santiago, 2016

FAZIO, Hugo: Los mecanismos fraudulentos de hacer fortuna. LOM, Santiago, 2016.

FUENTES, Claudio: "La reforma a los partidos políticos. Modelos en pugna". En: Garretón, Manuel Antonio: La gran ruptura. Institucionalidad política y actores sociales en el Chile del siglo XXI. LOM, Santiago, 2016

GARRETÓN, Manuel Antonio: La gran ruptura. Institucionalidad política $y$ actores sociales en el Chile del siglo XXI. LOM, Santiago, 2016.

GARRETÓN, Manuel Antonio: La gran ruptura. Institucionalidad política $y$ actores sociales en el Chile del siglo XXI. LOM, Santiago, 2016.

GARRETÓN, Manuel Antonio: Neoliberalismo corregido, progresismo limitado. Los gobiernos de la Concertación en Chile, 1990-2010. CLACSO, Santiago, 2012.

HARVEY, David: Breve historia del neoliberalismo. Akal, Madrid, 2005.

HUNEEUS, Cristián: La democracia semisoberana: Chile después de Pinochet. Taurus, Santiago de Chile, 2014.

JESSOP, Bob: “El Estado y el poder". En: Revista internacional de filosofia iberoamericana y teoría social, 2014. pp. 19-35.

MATAMALA, Daniel: Poderoso caballero. El peso del dinero en la política chilena. Catalonia/Periodismo-UDP, Santiago, 2015. 
MiRANDA, Eduardo, y RODRÍGUEZ, Eduardo: Examen crítico del Sistema de AFP. Mitos y realidades. Editorial Universitaria, Santiago, 2002.

MÖNCKERBERG, María Olivia: El saqueo de los grupos económicos al Estado chileno. Debolsillo, Santiago, 2015.

MOULIAN, Tomás: Chile actual. Anatomía de un mito. LOM/Arcis, Santiago, 1997.

OSORIO, Jaime: Teoría marxista de la dependencia. Historia, fundamentos, debates y contribuciones. Itaca/UAM-x, México, 2016.

POULANTZAS, Nicos: Estado, poder y socialismo. Fondo de Cultura Económica, México, 1979.

RUIZ, Carlos: "Crisis política en Chile: neoliberalismo, cambios sociales y democracia". En: La gran ruptura. Institucionalidad política y actores sociales en el Chile del siglo XXI, de Manuel Antonio Garretón, 83-108. LOM, Santiago, 2016.

RUIZ, Carlos y BOCCARDO, Giorgio: Los chilenos bajo el neoliberalismo. Clases y conflicto social. El Desconcierto/ Nodo XXI, Santiago, 2015.

VALENZUELA, Esteban: La conversión de los socialistas chilenos. Esquema de transformación político-cultural de una élite desde la revolución al orden. El Desconcierto, Santiago, 2014. 